
About IJMA [last updated July, $\left.1^{\text {st }}, 2021\right]$

$\checkmark$ International Journal of Medical Arts is the Official Journal of the Damietta Faculty of Medicine, AlAzhar University, Egypt

$\checkmark$ It is an International, Open Access, Double-blind, Peer-reviewed Journal

$\checkmark$ Published four times a year

$\checkmark$ The First Issue was published in July 2019

$\checkmark$ Published under the following license: Creative Commons Attribution-ShareAlike 4.0 International Public License (CC BY-SA 4.0). It had updated from the Creative Commons license [CC BY] in volume 2, Issue 4, October 2020 About IJMA

$\checkmark$ The Egyptian Knowledge Bank hosts the web site of IJMA

$\checkmark$ The Egyptian Knowledge Bank supports IJMA

$\checkmark$ IJMA follows the regulations of the International Committee of Medical Journal Editors

$\checkmark$ IJMA is indexed in the "Directory of Open Access Journals" [15 January 2021].

$\checkmark$ IJMA is indexed in JGate [29-6-2021]

$\checkmark$ IJMA is a member of the International Society of Managing and Technical Editors

$\checkmark$ Listed in "Index Copernicus", "Publons", "Academic resource index [ResearchBib]", "Electronics journal library", "Eurasian Scientific Journal Index", and "Citefactor"

$\checkmark$ IJMA introduced to the search engine [BASE] through DOAJ
Click image to reach the page

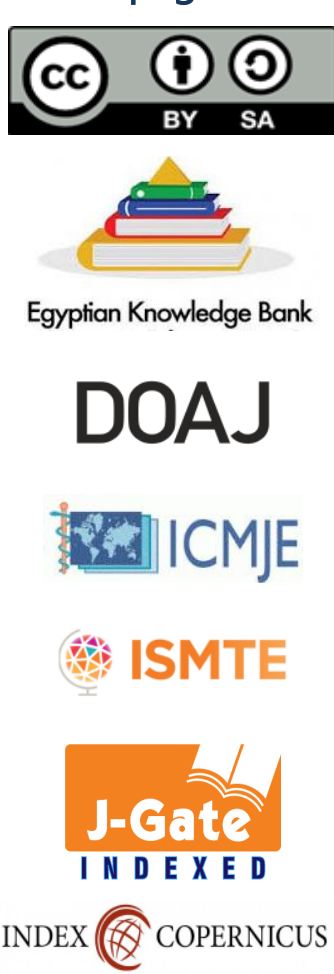

publons

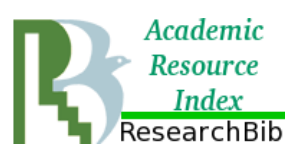

\section{EZ3 \\ .}

ESJII

CiteFactor

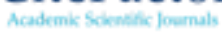

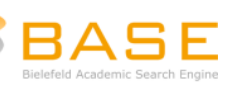




Available online at Journal Website
https://ijma.journals.ekb.eg/
Main subject [Anesthesia and Intensive Care]

Original Article

\title{
Comparison between the Effect of Trendelenburg 20 Degree and Straight Leg Raising 45 Degree Positions on The Hemodynamics After Tourniquet Deflation in Knee Arthroscopy
}

\author{
Ahme Mohammed Sonbol, Sameh Ghareeb \\ Department of Anesthesia and Intensive Care, Faculty of Medicine, Mansoura University, Egypt \\ Corresponding author: Ahme Mohammed Sonbol \\ Email: dr.sonbol@gmail.com
}

Submission date: February 09, 2021; Revision date: April 22, 2021; Acceptance date: April 23, 2021

DOAJ

DOI: 10.21608/IJMA.2021.62396.1262

\section{ABSTRACT}

Background: Deflation of the pneumatic tourniquet after orthopedic surgery is associated with multiple cardiovascular adverse effects [hypotension and tachycardia]. Trendelenburg position or passive leg raising [PLR] are commonly used as the initial treatment of shock and hypotension

Aim of the work: To compare between Trendelenburg position $20^{\circ}$ and passive leg raising $45^{\circ}$ regarding the incidence of posttourniquet deflation cardiovascular adverse effects in patients undergoing unilateral knee arthroscopy.

Patients and methods: This prospective study included 98 cases that underwent unilateral knee arthroscopy. Patients were randomly allocated into two groups; group [1] included 49 cases who were exposed to the Trendelenburg position after deflation, and group [2] included the remaining cases who had the straight leg raising test after deflation. Mean arterial pressure, heart rate, and need for vasoactive substances were recorded.

Results: No significant difference was noticed between the two groups regarding demographic variables, heart rate before tourniquet deflation, and one-minute after its deflation. However, there was a significant difference between the same groups on the subsequent readings apart from the last one. Also, group [1] showed significantly higher mean arterial pressure [MAP] compared to group [2] after deflation. Hypotension was more significantly encountered in group [2], and thus ephedrine requirements were increased.

Conclusion: Trendelenburg position appears to be more efficacious when compared to the straight leg raising, regarding the prevention of cardiovascular adverse effects associated with deflation.

Keywords: Trendelenburg Position; Straight Leg Raising Test; Tourniquet Deflation; Knee Surgery; Hypotension.

This is an open-access article registered under the Creative Commons, ShareAlike 4.0 International license [CC BY-SA 4.0] [https://creativecommons.org/licenses/by-sa/4.0/legalcode.

Citation: Sonbol AM, Ghareeb S. Comparison between the Effect of Trendelenburg 20 Degree and Straight Leg Raising 45 Degree Positions on The Hemodynamics After Tourniquet Deflation in Arthroscopy. IJMA 2021; 3 [3] July-September: 1500-1506. [DOI: 10.21608/IJMA.2021.62396. 1262].

${ }^{*}$ Main subject and any subcategories have been classified according to the research topic. 


\section{INTRODUCTION}

In orthopedic surgeries, the pneumatic tourniquet is usually used at it helps to decrease operative bed bleeding, and thus, maintaining a clean and dry surgical field allowing easy and clear identification of the anatomical structures. Despite that advantage, after its deflation, there is a blood volume shift towards that ischemic area, which may decrease cardiac preload leading to hypotension [1].

Hemodynamic changes after tourniquet deflation include; hypotension, tachycardia and increase in cardiac index [2].

These changes may be insignificant for healthy individuals but, risky for patients with compromised cardiovascular system and geriatric population [2,3].

Hypovolemia is a common problem in many clinical situations. The mortality of hypovolemic shock is directly related to the severity and duration of organ hypoperfusion; prompt volume replacement is the hallmark of success in managing the hypovolemic patient [4]. However, since fluid resuscitation requires some time to accomplish, maneuvers such as the Trendelenburg position or passive leg raising [PLR] are commonly used as the initial treatment of shock and hypotension [4].

Trendelenburg position is used as a recovery maneuver in patients with shock, as it increases venous return, cardiac output, and enhances tissue perfusion. It means elevation of the patient pelvis above the horizontal plane in the supine position. Since World War-I, this position along with its variations [supine position with passive leg raising] have been used in patients with symptomatic hypotension [5].

Passive leg raising test has been used to predict fluid responsiveness in critically ill patients. That test is based on a simple fact, raising the limb upwards will aid the blood contained in the lower limb vasculature to be auto-transfused in the circulation, leading to an increase in the cardiac preload [6-8].

\section{AIM OF THE WORK}

The current work designed to compare between Trendelenburg position $20^{\circ}$ and straight leg elevation $45^{\circ}$ regarding the incidence of post-tourniquet deflation cardiovascular adverse effects in patients undergoing unilateral knee arthroscopy.

\section{PATIENTS AND METHODS}

This prospective study was conducted at Mansoura University Hospitals during the period between January and July 2020. We included a total of 98 cases who underwent a unilateral knee arthroscopy after obtaining written consent from all cases. The study was approved by the local ethical committee of Mansoura University.

Inclusion criteria: cases older than 18 years who underwent a unilateral knee arthroscopy requiring the application of proximal tourniquet.

Exclusion criteria: cases with previous knee surgery, cardiac arrhythmia, uncontrolled systemic hypertension, unstable angina, requiring bilateral lower limb surgery and cases having American Society of Anesthesiologists [ASA] $>$ II.

All cases are subjected to

- Clinical and radiological assessment before surgery.

- Crystalloid solution administration. At 80 to 100 $\mathrm{ml} / \mathrm{h}$ for the $2 \mathrm{~h}$ immediately before surgery.

- Fentanyl and/or midazolam administration for anxiolysis 5 min before induction of anesthesia.

- Vital signs monitoring as heart rate, invasive arterial blood pressure [for more accurate reading] temperature, and pulse oximetry on reaching operating theatre.

Spinal anesthesia was performed in the L3-L4 interspace via a 25-gauge spinal needle after local skin sterilization, and infiltration with $2 \mathrm{~mL}$ of $2 \%$ lidocaine was done with a single dose of $15 \mathrm{mg}$ hyperbaric bupivacaine $0.5 \%$ [3 ml] injected over 30 seconds.

Hypotension [fall of MAP by $20 \%$ or more from basal value] was corrected by fluid supplementation and/or $5 \mathrm{mg}$ of ephedrine incremental. 
Bradycardia [HR $<50 \mathrm{bpm}]$ was treated with incremental $0.5 \mathrm{mg}$ of intravenous [IV] atropine. After anesthesia, the patient was placed at the supine position, and a proximal pneumatic tourniquet was applied [pressure $300-350 \mathrm{mmHg}$ ], and the operation was performed.

Monitoring of hemodynamics was done throughout the procedure as systolic blood pressure [SBP], diastolic blood pressure [DBP] and mean arterial pressure [MAP] via noninvasive, automated methods. The continuous electrocardiogram [ECG] allowed measurements of heart rate [HR] [Datex Ohmeda S/5 anesthesia monitor, GE Healthcare, Chalfont St. Giles, UK].

In addition, we recorded the doses of bupivacaine, ephedrine administrated and the total volume of fluid administered before tourniquet deflation.

Patients were randomly divided into two groups following completion, and before tourniquet deflation using the closed envelope method. Group 1: 49 cases that had their position changed to the Trendelenburg position with head down tilt to $20^{\circ}$; Group 2: the remaining 49 cases who had bilateral passive leg raising to $a 5^{\circ}$ angle.

Outcome was estimated by mean arterial pressure [MAP], heart rate and need for vasopressors before deflation, and at 1-, 2-, 3-, 4-, 5-, and 10 minutes after deflation.

\section{Statistical Analysis:}

Data were analyzed using the Statistical Package of Social Science [SPSS] program for Windows [Standard version 21] [IBM $B S P S S \circledR$ Inc., Chicago, USA]. The normality of data was first tested with onesample Kolmogorov-Smirnov test. Qualitative data were described using number and percent. Association between categorical variables was tested using Chisquare test. Continuous variables were presented as mean $\pm S D$ [standard deviation] for parametric data. The two groups were compared with Student " $t$ " test. $P$ value $<0.05$ was considered statistically significant.

\section{RESULTS}

As regard demographic data, the mean age of the included cases was 25.9 and 29.49 years in groups $A$ and $B$ respectively. The percentages of females in group 1 were 51 while in group 2 was $61.2 \%$ The mean values of body mass indices [BMI] were 26.78 and $28.06 \mathrm{~kg} / \mathrm{m}^{2}$ in group 1 and 2 respectively. In addition, the majority of cases in study were ASA score I. All of the previously mentioned variables were not statistically significant between the two groups [p > 0.05] [Table 1].

Regarding heart rate, there was no significant difference between the two groups before tourniquet deflation, and 1-minute after its deflation. However, there was a significant difference between two groups on the subsequent readings [2-, 3-, 4-, and 5-minute readings, $p<0.05]$, as group 1 showed significantly lower heart rates compared to the other group. The 10minute reading did not differ between the two groups [ $p$ $=0.174]$ [Table 2].

There was no significant difference between the two groups regarding MAP before deflation. Nevertheless, group 1 showed significantly higher MAP compared to group 2 after deflation [p < 0.001] [Table 3].

Hypotension was encountered in only one case [2\%] in group 1, whereas it was encountered in 7 cases [14.3\%] in group 2 [ $p=0.027$ ]. ephedrine usage was significantly increased in the second group compared to the first one [2.35 vs. $0.2 \mathrm{mg}, p=0.025$ ] [Table 4].

Table [1]: Demographic data in the studied groups.

\begin{tabular}{|c|c|c|c|c|c|}
\hline & Group 1 [n= 49] & Group 2 [n= 49] & $95 \% \mathrm{Cl}$ & $\mathrm{p}$ \\
\hline \multicolumn{2}{|c|}{ Age [years] } & $25.90 \pm 10.341$ & $29.49 \pm 9.170$ & $-7.51,0.33$ & 0.072 \\
\hline \multirow[t]{2}{*}{ Gender } & Male & $49.0 \%[24]$ & $38.8 \%[19]$ & \multirow[t]{2}{*}{$-0.3,0.09$} & \multirow[t]{2}{*}{0.309} \\
\hline & Female & $51.0 \%[25]$ & $61.2 \%[30]$ & & \\
\hline \multicolumn{2}{|c|}{$\mathrm{BMI}\left[\mathrm{kg} / \mathrm{m}^{2}\right]$} & $26.78 \pm 4.987$ & $28.06 \pm 4.340$ & \multirow{3}{*}{$\frac{-3.15,0.60}{-0.11,0.19}$} & 0.179 \\
\hline \multirow[t]{2}{*}{ ASA } & $\mathrm{I}$ & $81.6 \%[40]$ & $85.7 \%[42]$ & & \multirow[t]{2}{*}{0.585} \\
\hline & II & $18.4 \%$ [9] & $14.3 \%[7]$ & & \\
\hline
\end{tabular}


Table [2]: Heart rate variation before and after tourniquet deflation in the studied groups.

\begin{tabular}{|l|c|c|c|c|}
\hline \multicolumn{1}{|c|}{ Heart rate } & Group 1 [n= 49] & Group 2 [n= 49] & $95 \% \mathrm{Cl}$ & $\mathrm{p}$ \\
\hline Before deflation & $79.24 \pm 10.315$ & $82.61 \pm 12.320$ & $-7.92,1.19$ & 0.146 \\
\hline One minute & $83.24 \pm 11.163$ & $87.96 \pm 13.430$ & $-9.67,0.24$ & $<.062$ \\
\hline Two minutes & $85.41 \pm 11.869$ & $93.65 \pm 14.326$ & $-13.52,-2.97$ & $<0.001$ \\
\hline Three minutes & $86.14 \pm 12.295$ & $97.02 \pm 14.749$ & $-16.32,-5.43$ & $<0.001$ \\
\hline Four minutes & $86.39 \pm 12.528$ & $97.65 \pm 15.019$ & $-16.81,-5.72$ & $-17.88,-6.82$ \\
\hline Five minutes & $83.88 \pm 12.313$ & $96.22 \pm 15.128$ & $-7.95,1.46$ & 0.174 \\
\hline 10 minutes & $79.41 \pm 10.970$ & $82.65 \pm 12.458$ & 001 \\
\hline
\end{tabular}

Table [3]: Mean arterial blood pressure variation before and after tourniquet deflation in the studied groups.

\begin{tabular}{|l|c|c|c|c|}
\hline \multicolumn{1}{|c|}{ MAP } & Group 1 [n= 49] & Group 2 [n= 49] & $95 \% \mathrm{Cl}$ & $\mathrm{p}$ \\
\hline Before deflation & $96.57 \pm 8.127$ & $96.31 \pm 7.851$ & $-2.94,3.47$ & 0.870 \\
\hline One minute & $94.41 \pm 9.004$ & $85.43 \pm 9.213$ & $5.33,12.63$ & $<0.001$ \\
\hline Two minutes & $91.06 \pm 7.915$ & $82.22 \pm 8.806$ & $5.48,12.19$ & $<0.001$ \\
\hline Three minutes & $89.45 \pm 7.887$ & $81.43 \pm 7.411$ & $4.95,11.09$ & $<0.001$ \\
\hline Four minutes & $90.71 \pm 8.302$ & $82.49 \pm 7.174$ & $5.11,11.34$ & $<0.001$ \\
\hline Five minutes & $91.61 \pm 8.553$ & $84.22 \pm 8.055$ & $4.06,10.72$ & $<0.001$ \\
\hline Ten minutes & $98.92 \pm 9.416$ & $90.45 \pm 8.813$ & $4.81,12.13$ & $<0.001$ \\
\hline
\end{tabular}

Table [4]: Incidence of hypotension and Ephedrine dose [mg] in the studied groups.

\begin{tabular}{|l|c|c|c|c|}
\hline & Group 1 [n= 49] & Group 2 [n= 49] & $95 \% \mathrm{Cl}$ & $\mathrm{p}$ \\
\hline Hypotension & $2.0 \%[1]$ & $14.3 \%[7]$ & $0.02,0.23$ & 0.027 \\
\hline Ephedrine & $0.20 \pm 1.429$ & $2.35 \pm 6.132$ & $-3.93,-0.36$ & 0.025 \\
\hline
\end{tabular}

\section{DISCUSSION}

Both Trendelenburg and straight leg raising positions are used for the management of acute hypotension [9].

To the best of our knowledge, there is a paucity of studies comparing both positions in the prevention of cardiovascular adverse effects associated with tourniquet deflation during lower limb orthopedic surgeries.

This study was conducted to elucidate the difference between these two positions regarding the incidence of tachycardia and hypotension after tourniquet deflation in knee arthroscopy surgery.
As shown in the methodology, the included cases were randomly divided into two groups with no significant differences regarding demo-graphics, and that ensures the good randomization and reliability of our data.

Multiple studies have reported blood pressure decrease after tourniquet deflation. Kahn and his associates reported a $19.2 \%$ decrease in MAP 1 minute after tourniquet deflation during knee arthroplasty procedures [10].

Girardis et al. also reported a 14\% decrease in the same parameter with tourniquet deflation [11].

Furthermore, Iwama et al. reported a 14.5 and 
$12.9 \%$ decrease in systolic and diastolic blood pressure respectively following deflation of the tourniquet in lower limb surgery [12].

Regarding the passive leg raising test, in a previous study conducted by Huang et al., passive leg raising was successful in preventing hypotension after tourniquet deflation compared to controls. There was a $15.1 \%$ decrease in MAP in controls, while the decrease was $4.3 \%$ in the leg raising group. Therefore, it helped to maintain hemodynamic stability after deflation compared to controls [13].

This effect could be explained by three mechanisms; first of all, rising the leg helps to move blood from the lower limb vasculature, by the effect of gravity, to the intrathoracic veins, leading to an increase in cardiac preload $[14,15]$.

Secondly, straight leg raising is associated with an increased systemic vascular resistance $[16,17]$.

Lastly, with the leg elevated during deflation, the blood shift to the ischemic limb will be significantly decreased by the effect of the gravity, that counteracts the blood flow [13].

However, leg rising is not always sufficient to prevent these cardiac adverse effects. Huang et al. reported that MAP decreased by $5 \%$ or more in $54.28 \%$ of the included cases. That means that it cannot completely counteract the adverse effects following tourniquet deflation [13].

This could be explained by the fact that hypotension and tachycardia are multifactorial. Not only is rapid shift of blood to the ischemic limb responsible for hemodynamic changes, but also decreased vascular resistance, operative blood loss, and the circulatory effects of the accumulated metabolites may have a role in these manifestations $[11,18,19]$.

Also, Wong et al. reported that straight leg raising decreased MAP due to a decrease in the diastolic pressure. Thus, there an obvious variability in the MAP responses to leg elevation among patients in different studies [20].

In addition, other multiple studies have negated any significant effect of leg rising on the heart rate [16, 20-22].
Due to the previous weak efficacy reported by the straight leg raising test, we tried to compare it with the original Trendelenburg position aiming to obtain better results in such cases.

Our results revealed that hypotension and tachycardia were significantly more encountered in the leg raising group after deflation. Also, the incidence of hypotension was higher which led to an increase in ephedrine injection requirements in the leg raising group.

According to a previous meta-analysis [23], had compared the hemodynamic changes between the two positions. Although they noticed an increase in cardiac output after both positions after one minute of application, which was more in Trendelenburg position. No conclusions could be reached regarding the effect after 10 minutes. They stated that Leg rising, in contrast, seems to have a sustained effect. However, as they use wide range definition of Trendelenburg position, total-body head down tilt of $5^{\circ}$ to $60^{\circ}$, and PLR was defined as supine position with straight passive elevation of both legs at a $10^{\circ}$ to $90^{\circ}$ angle in the studies included in this meta- analysis, small sample size of studies, also variable patients' criteria; normoand hypovolemic patients, so more direct and specific comparison is needed.

Other studies have compared the hemodynamic changes between the two positions [14, 24-26] and effect on heart dimensions, showed that both approaches of volume loading of the heart induced significant changes and increases of preload. However, changes were more pronounced during the "leg up" position $45^{\circ}$ than during HDT of $6^{\circ}$. It is questioned whether HDT with $-6^{\circ}$ is appropriate to truly reflect hemodynamic alterations of Trendelenburg position. But they concluded that "leg up" position cannot be maintained as long as HDT due to decrease of arterial blood supply thus causing discomfort [23].

In our study, the application of Trendelenburg position of $20^{\circ}$ had also other advantages; it was easy to apply in the modern operating tables without any negative impact on the sterilized operative field. Even if manual work was required, it was adjusted from the table control located at the patient's head without compromising the operative field. On the other hand, 
leg raising may require some manual interference in some operating tables, and that caused some trouble to the surgical team and their sterilized operative filed. That point is of great importance, as after deflation, bleeding may appear in the operative field, which may mandate control. Maintaining the cleanliness of the operative field is mandatory for that step. Also, in Trendelenburg position, the patient has no flexed hip, unlike leg raising, which may interfere with the surgeon orientation in other orthopedic surgeries.

Although the Trendelenburg position has been associated with gastric content regurgitation, respiratory difficulty, increased intraocular and intracranial pressures [27-29], neither of these reported drawbacks had been reported in our study. This could be due to the short time period at which the patient is positioned that way.

Our study has some limitations, first, it is a single center study. Secondly, the cardiac output [COP] should have been measured in the included cases to know the effect of both positions on COP. These drawbacks should be covered in the upcoming studies.

Conclusion: Based on the current findings, Trendelenburg position appears to be more efficacious, compared to the straight leg raising, regarding the prevention of cardiovascular adverse effects associated with tourniquet deflation.

Financial and Non-Financial Relationships and Activities of Interest

None

\section{REFERENCES}

1. Kumar K, Railton C, Tawfic Q. Tourniquet application during anesthesia: "What we need to know?". J Anaesthesiol Clin Pharmacol. 2016; 32 [4]: 424. [DOI:10.4103/0970-9185.168 174]

2. Zarrouki $Y$, Abouelhassan T, Samkaoui MA. Cardiac arrest after tourniquet deflation in upper limb. Trauma Case Rep. 2017;7:1-2. [DOI: 10.1016/j.tcr.2017.01.001]

3. Huh IY, Kim D-Y, Lee J-H, Shin SJ, Cho YW, Park SE. Relation between preoperative autonomic function and blood pressure change after tourniquet deflation during total knee replacement arthroplasty. Korean J Anesthesiol. 2012; 62 [2]:154. [DOI:10.4097/kjae.2012.62.2.154].

4. Geerts BF, van den Bergh L, Stijnen T, Aarts LP, Jansen
JR. Comprehensive review: is it better to use the Trendelenburg position or passive leg raising for the initial treatment of hypovolemia? J Clin Anesth. 2012; 24 [8]: 66874. [DOI: 10.1016/j.jclinane.2012.06.003].

5. Ballesteros-Peña S, Larrad AR. Does the Trendelenburg position affect hemodynamics? A systematic review. Emerg. 2012; 24: 143-50.

6. Monnet X, Rienzo M, Osman D, Anguel N, Richard C, Pinsky MR, et al. Passive leg raising predicts fluid responsiveness in the critically ill. Crit Care Med. 2006; 34 [5]:1402-7. [DOI: 10.1097/01.CCM.0000215453.11735.06]

7. Boulain T, Achard JM, Teboul JL, Richard C, Perrotin D, Ginies G. Changes in BP induced by passive leg raising predict response to fluid loading in critically ill patients. Chest. 2002;121[4]:1245-52. [DOI:10.1378/chest.121.4. 1245].

8. De Backer D. Can passive leg raising be used to guide fluid administration? Crit Care. 2006;10 [6]: 170. [DOI:10.1186/ cc5081].

9. Kweon TD, Jung CW, Park JW, Jeon YS, Bahk JH. Hemodynamic effect of full flexion of the hips and knees in the supine position: a comparison with straight leg raising. Korean J Anesthesiol. 2012; 62 [4]: 317-321. [DOI:10.4097/ kjae.2012.62.4.317].

10. Kahn RL, Sharrock NE, Urquhart B, Marino V. Hemodynamic changes associated with tourniquet use under epidural anesthesia for total knee arthroplasty. Reg Anesth. 1992; 17 [4]:228-32. [DOI:10.1097/00000542-19890900100077].

11. Girardis M, Milesi S, Donato S, Raffaelli M, Spasiano A, Antonutto $\mathrm{G}$, et al. The hemodynamic and metabolic effects of tourniquet application during knee surgery. Anesth Analg. 2000; 91 [3]:727-31. [DOI:10.1097/00000539-20000900000043].

12. Iwama H, Kaneko T, Ohmizo H, Furuta S, Ohmori S, Watanabe K. Circulatory, respiratory and metabolic changes after thigh tourniquet release in combined epiduralpropofol anaesthesia with preservation of spontaneous respiration. Anaesth. 2002;57[6]:588-92. [DOI:10.1046/j. 1365-2044.2002.02509_2.x].

13. Huang GS, Wang $\mathrm{CC}, \mathrm{Hu} \mathrm{MH}$, Cherng $\mathrm{CH}$, Lee MS, Tsai $\mathrm{CS}$, et al. Bilateral passive leg raising attenuates and delays tourniquet deflation-induced hypotension and tachycardia under spinal anaesthesia: a randomised controlled trial. Eur J Anaesthesiol. 2014; 31 [1]: 15-22. [DOI:10.1097/EJA. 0b013e32836286e3].

14. Reich DL, Konstadt SN, Raissi S, Hubbard M, Thys DM. Trendelenburg position and passive leg raising do not significantly improve cardiopulmonary performance in the anesthetized patient with coronary artery disease. Crit Care Med. 1989;17[4]:313-7. [DOI:10.1097/00003246-198904 000-00003].

15. Rutlen DL, Wackers FJ, Zaret BL. Radionuclide assessment 
of peripheral intravascular capacity: a technique to measure intravascular volume changes in the capacitance circulation in man. Circ. 1981; 64[1]: 146-52. [DOI: 10.1161/01.cir.64. 1.146].

16. Gaffney FA, Bastian BC, Thal ER, Atkins JM, Blomqvist CG. Passive leg raising does not produce a significant or sustained autotransfusion effect. J Trauma Acute Care Surg. 1982; 22 [3]: 190-3. [DOI:10.1097/00005373-19820 3000-00003].

17. Tempe DK, Khanna S, Juneja R, Mehta $Y$, Tandon MS, Dhar $A$, et al. Haemodynamic effects of leg raising in patients undergoing coronary artery bypass grafting. Indian Heart J. 1999; 51 [2]:173-7. [PMID: 10407545].

18. 18. Collis MG. The vasodilator role of adenosine. Pharmacol Ther. 1989; 41[1-2]:143-62. [DOI:10.1016/0163-7258[89] 90104-6].

19. Benzon HT, Toleikis JR, Meagher LL, Shapiro BA, Ts'ao $\mathrm{CH}$, Avram MJ. Changes in venous blood lactate, venous blood gases, and somatosensory evoked potentials after tourniquet application. Anesthesiol. 1988; 69[5]:677-82. [DOI:10.1097/00000542-198811000-00007].

20. Wong DH, Tremper KK, Zaccari J, Hajduczek J, Konchigeri $\mathrm{HN}$, Hufstedler SM. Acute cardiovascular response to passive leg raising. Crit Care Med. 1988;16 [2]:123-5. [DOI:10.1097/00003246-198802000-00005].

21. Kyriakides ZS, Koukoulas A, Paraskevaidis IA, Chrysos D, Tsiapras D, Galiotos C, et al. Does passive leg raising increase cardiac performance? A study using Doppler echocardiography. Int J Cardiol. 1994; 44[3]: 288-93. [DOI:10.1016/0167-5273[94]90294-1].

22. McHugh GJ, Robinson BJ, Galletly DC. Leg elevation compared with Trendelenburg position: effects on autonomic cardiac control. Br J Anaesth. 1994; 73 [6]: 8367. [DOI:10.1093/bja/73.6.836].
23. Geerts BF, van den Bergh $L$, Stijnen $T$, Aarts LP, Jansen JR. Comprehensive review: is it better to use the Trendelenburg position or passive leg raising for the initial treatment of hypovolemia? J Clin Anesth. 2012;24[8]:66874. [DOI: 10.1016/j.jclinane.2012.06.003].

24. Terai C, Anada H, Matsushima S, Kawakami M, Okada Y. Effects of Trendelenburg versus passive leg raising: autotransfusion in humans. Intensive Care Med. 1996; 22 [6]: 613-4. [DOI:10.1007/BF01708113].

25. Ostrow CL, Hupp E, Topjian D. The effect of Trendelenburg and modified trendelenburg positions on cardiac output, blood pressure, and oxygenation: a preliminary study. Am J Crit Care. 1994; 3[5]:382-6. [PMID: 8000462].

26. Dirschedl $P$, Gregull $A$, Löllgen $H$. Volume loading of the heart by "leg up" position and head down tilting $\left[-6^{\circ}\right][\mathrm{HDT}]$. Acta astronautica. 1992;27:41-3. [DOI:10.1016/0094-5765 [92] 90173-G].

27. Mansour AM, Feghali JG, To'mey K, Jaroudi N. Increased intraocular pressure with head-down position. Am J Ophthalmol. 1984; 98[1]:114-5. [DOI:10.1016/0002-9394 [84] 90200-9].

28. Johnson S, Henderson SO. Myth: The Trendelenburg position improves circulation in cases of shock. CJEM. 2004; 6[1]:48-9. [DOI:10.1017/s1481803500008915].

29. Mavrocordatos P, Bissonnette B, Ravussin P. Effects of neck position and head elevation on intracranial pressure in anaesthetized neurosurgical patients: preliminary results. J Neurosurg Anesthesiol. 2000;12 [1]: 10-4. [DOI:10.1097/ 00008506-200001000-00003]. 

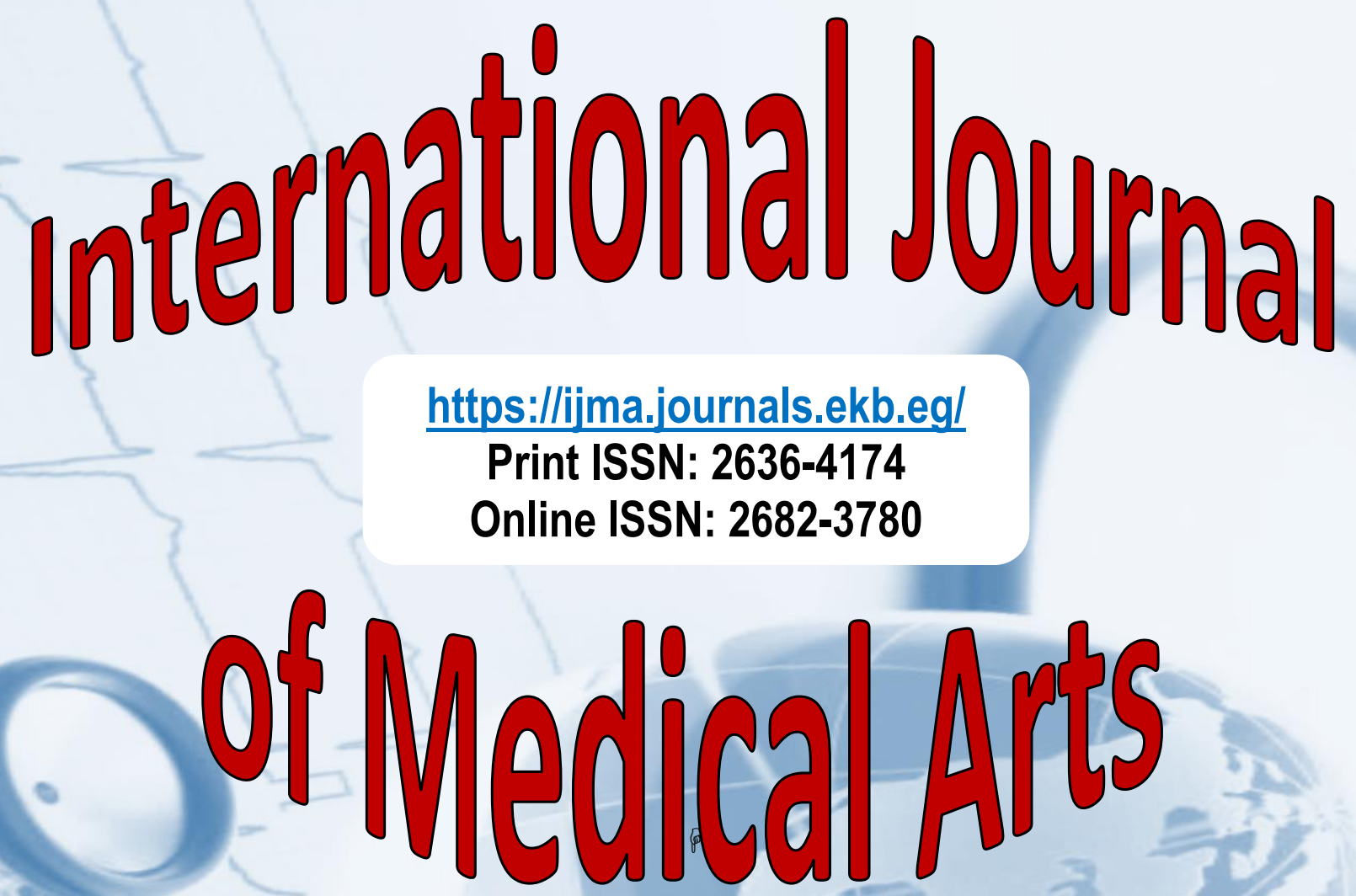